activity and depression. Full names of questionnaires are listed in the table 1 Data are presented as mean \pm SEM.

Results: Compared to HC, patients with SSc had significantly higher prevalence and greater severity of sexual dysfunction (FSFI, BISF-W: in all subscales as well as total scores), dysfunction of pelvic floor (PISQ-12, PFIQ7), and worse sexual quality of life (SQol-F) (table 1). Worse scores in SSc patients were associated with higher disease activity [ESSG activity index: SQol-F $(r=-0.364, p=0.0443)$, PFIQ7-gynaecological subscale $(r=0.492, p=0.0036)$ ], greater fatigue [all three questionnaires FSS/FIS/MAF correlated negatively with FSFI, BISF-W], more severe depression [BDI-II: FSFI $(r=-0.553, p=0.0002)$, BISF-W $(r=-0.514$, $\mathrm{p}=0.0007)$, PFIQ7 $(\mathrm{r}=0.495, \mathrm{p}=0,0010)]$, deteriorated quality of life [SHAQ: FSFI $(r=-0.536, p=0.0003), \quad B I S F-W \quad(r=-0.563, p=0.0001), \quad S Q o l-F \quad(r=-0.338$, $\mathrm{p}=0.0382)$, PISQ-12 $(\mathrm{r}=0.563, \mathrm{p}=0.0051), \mathrm{PFIQ7}(\mathrm{r}=0.380, \mathrm{p}=0.0142)]$, and worse ability to perform physical activities [HAP: FSFI $(r=0.407, p=0.0082)$, BISF-W $(r=0.409, p=0.0078)]$

\begin{tabular}{|c|c|c|c|}
\hline Questionnaire: score range & $\begin{array}{c}\text { Systemic } \\
\text { sclerosis } \\
(n=41)\end{array}$ & $\begin{array}{c}\text { Healthy } \\
\text { controls } \\
(n=41)\end{array}$ & p-value \\
\hline $\begin{array}{l}\text { FSFI: Female Sexual Function Index: 2(worst)- } \\
36 \text { (best) }\end{array}$ & $15.2 \pm 1.7$ & $25.0 \pm 1.7$ & $\mathrm{p}<0.0001$ \\
\hline $\begin{array}{l}\text { BISF-W: Brief Index of Sexual Function for } \\
\text { Women: }-16 \text { (worst) }-75 \text { (best) }\end{array}$ & $17.5 \pm 2.8$ & $29.7 \pm 2.8$ & $\mathrm{p}=0.0027$ \\
\hline $\begin{array}{l}\text { PISQ-12: Pelvic Organ Prolapse/Urinary } \\
\text { Incontinence Sexual Questionnaire short form: } \\
0 \text { (best)-48(worst) }\end{array}$ & $13.9 \pm 0.9$ & $8.5 \pm 0.7$ & $\mathrm{p}<0.0001$ \\
\hline $\begin{array}{l}\text { PFIQ7: Pelvic Floor Distress Inventory } \\
\text { Questionnaire - short form 7: } \\
\text { 0(best)-300(worst) }\end{array}$ & $26.4 \pm 5.9$ & $7.1 \pm 2.2$ & $\mathrm{p}=0.0092$ \\
\hline $\begin{array}{l}\text { SQoL-F: Sexual Quality of Life Questionnaire - } \\
\text { Female: } 0 \text { (worst) }-100 \text { (best) }\end{array}$ & $56.7 \pm 3.9$ & $78.8 \pm 3.3$ & $\mathrm{p}<0.0001$ \\
\hline FSS: Fatigue Severity Scale: 9(best)-63(worst) & $40.7 \pm 2.2$ & $6.9 \pm 1.0$ & $\mathrm{p}<0.0001$ \\
\hline FIS: Fatigue Impact Scale: 0 (best) -160 (worst) & $59.2 \pm 4.9$ & $28.8 \pm 4.3$ & $\mathrm{p}<0.0001$ \\
\hline $\begin{array}{l}\text { MAF: Multidimensional Assessment of Fatigue } \\
\text { Scale: } 1 \text { (best) }-50 \text { (worst) }\end{array}$ & $26.0 \pm 1.6$ & $13.6 \pm 1.3$ & $\mathrm{p}<0.0001$ \\
\hline $\begin{array}{l}\text { BDI-II: Beck's Depression Inventory II: 0(best)- } \\
63 \text { (worst) }\end{array}$ & $14.2 \pm 1.3$ & $4.8 \pm 0.8$ & $\mathrm{p}<0.0001$ \\
\hline $\begin{array}{l}\text { HAP: Human Activity Profile-adjusted activity } \\
\text { score: } 0 \text { (worst)-94(best) }\end{array}$ & $49.4 \pm 3.7$ & $81.1 \pm 1.5$ & $p<0.0001$ \\
\hline $\begin{array}{l}\text { HAQ: Health Assessment Questionnaire: } 0 \\
\text { (best)-3(worst) }\end{array}$ & $0.9 \pm 0.1$ & $0.1 \pm 0.0$ & $\mathrm{p}<0.0001$ \\
\hline
\end{tabular}

Conclusions: Women with SSc reported significantly impaired sexual function, sexual quality of life and pelvic floor function than age-matched healthy controls. Worse scores in SSc were associated with disease activity, physical activity, fatigue, depression and quality of life.

Acknowledgements: Supported by AZV-16- 33574A and MHCR 023728.

Disclosure of Interest: None declared

DOI: 10.1136/annrheumdis-2018-eular.7454

\section{SAT0484 PERFORMANCE OF THE 2017 EULAR/ACR CLASSIFICATION CRITERIA FOR INFLAMMATORY MYOSITIS AND THEIR MAJOR SUBGROUPS IN THE REMICAM (REGISTRY OF INFLAMMATORY MYOPATHIES IN THE MADRID COMMUNITY)}

E. Rabadán ${ }^{1}$, B.E. Joven ${ }^{1}$, F. Lozano ${ }^{1}$, L. Nuño ${ }^{2}$, F.J. López-Longo ${ }^{3}$, J. MartínezBarrios $^{3}$, C. Larena ${ }^{4}$, M. Blazquez ${ }^{4}$, C. Barbadillo ${ }^{5}$, I. Llorente ${ }^{6}$, A. Pérez ${ }^{7}$, T. Cobo ${ }^{8}$, R. Almodovar ${ }^{9}$, L. Lojo ${ }^{10}$, R. Calvo ${ }^{1}$, M.J. García de Yébenes ${ }^{11}$, P. E. Carreira ${ }^{1}$ on behalf of REMICAM group. ${ }^{1} \mathrm{H} 12$ Octubre; ${ }^{2} \mathrm{H} \mathrm{La} \mathrm{Paz} ;{ }^{3} \mathrm{H}$ Gregorio Marañón; ${ }^{4} \mathrm{H}$ Ramón y Cajal; ${ }^{5} \mathrm{H}$. Puerta de Hierro; ${ }^{6} \mathrm{H}$. La Princesa; ${ }^{7} \mathrm{H}$ Príncipe de Asturias; ${ }^{8} \mathrm{H}$ Infanta Sofía; ${ }^{9} \mathrm{H}$ Fundación Alcorcón; ${ }^{10} \mathrm{H}$ Infanta Leonor, ${ }^{11}$ Instituto musculoesquelético, Madrid, Spain

Background: A collaborative EULAR/ACR Project has developed new criteria for inflammatory myopathies $(\mathrm{IM})$ and their subgoups ${ }^{1}$

Objectives: To analyse agreement between the 2017 IM classification criteria and the Bohan and Peter(BP) criteria in REMICAM cohort ${ }^{2}$

Methods: All patients were included. New criteria were applied to obtain classification as: possible(Pos), probable(Pro) and definitive(Def) IM, and subclassification in 6 subgroups: polymyositis(PM), dermatomyositis(DM), juvenile DM(JDM), amiopathic DM(ADM), inclusion body myositis(IBM) and juvenile myositis(JM). The 7 subgroups in REMICAM were harmonised to fit the 6 subgroups of the 2017 criteria. Agreement between 2017 and BP criteria was analysed in classification/ subclassification, calculating the weighted kappa value (k). Subanalysis including only patients with available data on the muscle strength items required for the 2017 criteria, and in those having also muscle biopsy data, were conducted.

Results: From 479 REMICAM patients, 477 (99.6\%), fulfilled BP criteria $(5.9 \%$ Pos, 26.8\%Pro, 67.4\%Def) and 431 (89.9\%) 2017 criteria (2.5\%Pos, $21.8 \%$ Pro, 65.7 Def). Global agreement between both criteria was $89.5 \%$. Agreement between subtypes (Pos, Pro, Def) was low ( $k=0.15)$. When 399 patients with muscle strength data, and 243 with muscle biopsy data were analysed, results were similar $(k=0.17)$. Disagreement was mainly seen in Pos/Pro subtypes with BP criteria, since $60 \%$ classified as Def when the 2017 criteria were applied. Agreement in the different subgroups of IM (PM, DM, JDM, ADM, IBM, JM) between both criteria was very high $(\mathrm{k}=0.94)$.

Conclusions: The new 2017 EULAR/ACR criteria for IM classification show good agreement with BP criteria in the REMICAM cohort. New criteria classify $60 \%$ of Pos/Pro patients by BP criteria, as Def, and show very high agreement between IM subgroups. Validation studies are needed, but our results in this large cohort suggest the 2017 criteria might be useful for clinical trials and research in IM.

\section{REFERENCES:}

[1] Lundberg IE. Ann Rheum Dis 2017;76:1955-64.

[2] Nuño L. Rheumatol Clin 2017;13:331-7.

Disclosure of Interest: None declared

DOI: 10.1136/annrheumdis-2018-eular.6843

\section{SAT0485 WHAT IS THE EFFECT OF CYCLOPHOSPHAMIDE IV PULSE THERAPY IN PATIENTS WITH DIFFUSE CUTANEOUS SYSTEMIC SCLEROSIS ON SKIN INVOLVEMENT: AN OBSERVATIONAL STUDY}

B. Kersten, N. den Broeder, F. van den Hoogen, E. van den Ende, M. Vonk. Rheumatology, Radboud University Medical Center, Nijmegen, Netherlands

Background: Patients with systemic sclerosis who have proximal skin involvement are classified as diffuse cutaneous systemic sclerosis (DcSSc). Patients with progressive skin involvement have worse prognosis due to internal organ involvement. Treatment options of these patients consist among others of cyclophosphamide iv pulse therapy (iv $\mathrm{CYC}$ ). ${ }^{1}$ Recent studies show significant improvement of skin thickening in patients treated with $\mathrm{CYC}$ orally, ${ }^{2}$ but the effect of iv $\mathrm{CYC}$ on skin involvement remains unclear.

Objectives: To examine the extent of skin involvement during 12 monthly iv CYC $\left(750 \mathrm{mg} / \mathrm{m}^{2}\right)$ in DcSSc and to identify factors that predict response to therapy. Methods: Patients with DcSSc receiving iv CYC between 2004 and 2016 were included if they received at least 6 pulses. Skin involvement was accessed with the modified Rodnan Skinscore (mRSS) at baseline, month 6, 12, 24 and 36 by the same trained rheumatologist as part of routine care. Data of patients with the baseline measurement and at least one follow up measurement were included in the study. Missing mRSS data were imputed using multiple imputation by chained equation. Patients were classified as responders if the mRSS decreased at least 5 points and $25 \%$ from baseline at month 12 . A prediction model for response at 12 months was created using backwards logistic regression considering baseline variables and response at 6 months as possible predictors.

Results: A total of 99 patients were included. The mean improvement of mRSS over time was $-4.05(95 \% \mathrm{Cl}-5.53$ to -2.55$)$ (figure 1). $43 \%$ of patients had a response according to the response criteria.

Abstract SAT0485 - Table 1. Demographic and clinical characteristics of responders and non-responders

\begin{tabular}{lcc}
\hline & $\begin{array}{c}\text { Responders at 12 months } \\
(\mathrm{n}=40)\end{array}$ & $\begin{array}{c}\text { Non-responders at } \\
12 \text { months }(\mathrm{n}=51)\end{array}$ \\
\hline Age, mean (sd) & $52(14)$ & $54(13)$ \\
Female gender, $\mathrm{n}(\%)$ & $19(48 \%)$ & $19(37 \%)$ \\
Baseline mRSS, median (IQR) & $13(9-21)$ & $19(15-24)$ \\
Disease duration (months), & $3(1-12)$ & $6(2-18)$ \\
median (IQR) & & $37(73 \%)$ \\
infusions completed, $\mathrm{n}(\%)$ & $37(93 \%)$ & $14(27 \%)$ \\
12 & $3(8 \%)$ & $19(37 \%)$ \\
$\geq 6$ and<12 & $12(30 \%)$ & $29(57 \%)$ \\
Antibodies & $24(60 \%)$ & $1(2 \%)$ \\
-ANA & $17(46 \%)$ & \\
-Anti-topoisomerase & & \\
Response at 6 months & &
\end{tabular}

In univariate prediction models, baseline mRSS (OR 1.06, $\mathrm{p}=0.024)$, response at 6 months (OR: $37.45, p<0.001)$ and completed treatment (yes/no) (OR: 4.108 $\mathrm{p}=0.033$ ), were significant predictors of response at 12 months. For the last variable it should be mentioned that some patients who did not achieve a response at month 6 did not continue iv CYC for that reason. 


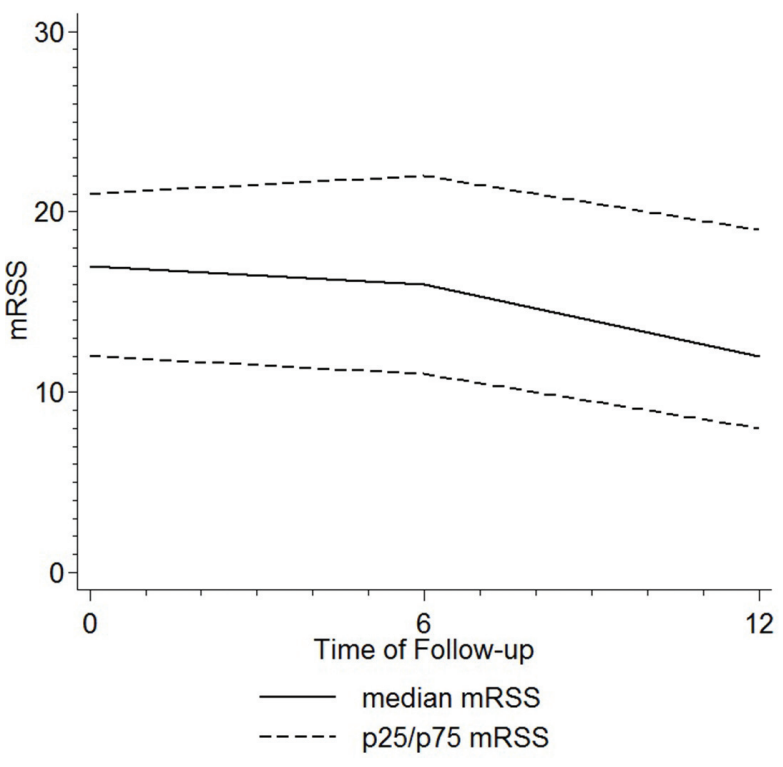

Abstract SAT0485 - Figure 1. mRSS course of all patients during iv CYC

Conclusions: This study shows that only $43 \%$ of the treated DcSSc patients experienced clinical important improvement of skin involvement following iv CYC. Response at month 6 is the best predictor for response on month 12. This could imply that at this time point, counselling about other available treatment options, should be considered in those patients.

\section{REFERENCES:}

[1] Kowal-Bielecka O, et al. EULAR recommendations for the treatment of systemic sclerosis: a report from the EULAR Scleroderma Trials and Research group (EUSTAR). Annals of the rheumatic diseases 2009;68 (5):620-8.

[2] Namas R, et al. Efficacy of mycophenolate mofetil and oral cyclophosphamide on skin thickness: Post-hoc analyses from the Scleroderma Lung Study I and II. Arthritis care \& research 2017.

Disclosure of Interest: None declared

DOI: 10.1136/annrheumdis-2018-eular.6768

\section{SAT0486 MYELOABLATION FOLLOWED BY AUTOLOGOUS STEM CELL RESCUE LEADS TO NORMALISATION OF SERUM IL-6 LEVELS IN PATIENTS WITH SYSTEMIC SCLEROSIS}

C. Bellocchi ${ }^{1}{ }^{2}$, K. Sullivan ${ }^{3}$, E. Goldmuntz ${ }^{4}$, J. Ying $^{1}$, L. Keyes-Elstein ${ }^{5}$, J. Varga ${ }^{6}$, M.E. Hinchcliff ${ }^{6}$, P. McSweeney ${ }^{7}$, D.E. Furst ${ }^{8}$, R. Nash ${ }^{7}$, L.J. Crofford ${ }^{9}$, B. Welch ${ }^{4}$, A. Pinckney ${ }^{5}$, M.D. Mayes ${ }^{1}$, S. Assassi ${ }^{1}{ }^{1}$ University of Texas Health Science Center at Houston, Houston, TX, USA; ${ }^{2}$ Scleroderma Unit, Referral Center for Systemic Autoimmune Diseases, Fondazione IRCCS Ca' Granda Ospedale Maggiore Policlinico di Milano, Milan, Italy; ${ }^{3}$ Duke University, Durham, NC;

${ }^{4}$ National Institute of Allergy and Infectious Diseases, Bethesda, MD; ${ }^{5}$ Rho Federal Systems Division, Chapel Hill, NC; ${ }^{6}$ Northwestern University, Chicago, IL; ${ }^{7}$ Colorado Blood Cancer Institute, Denver, CO; ${ }^{8}$ University of California Los Angeles, Los Angeles, CA; ${ }^{9}$ Vanderbilt University, Nashville, TN, USA

Background: In the randomised Scleroderma: Cyclophosphamide or Transplantation (SCOT) trial, myeloablation followed by autologous hematopoietic stem cell transplantation (HSCT) led to improved clinical outcomes compared to monthly cyclophosphamide (CYC) treatment in systemic sclerosis (SSc). ${ }^{1}$ Moreover, there is emerging evidence on the role of the Th2 cytokine, interleukin 6 (IL-6) in SSc pathogenesis, and clinical trials targeting the IL-6 pathway have been completed. $^{2}$

Objectives: To investigate the association of IL-6 with baseline clinical features and to examine its longitudinal changes in the treatment arms of the SCOT trials. Methods: The SCOT trial enrolled 75 subjects with diffuse SSc, 65 (HSCT $=31$, $\mathrm{CYC}=34$ ) subjects with a mean disease duration of 2.2 years were analysed; 65 age and gender matched controls were also investigated. All available serum samples at the baseline $(n=65)$, 8- $(n=55)$ and 26- $(n=45)$ month visits were included. IL-6 was determined using ultra-sensitive Simoa assay. For purposes of comparison, prominent, pro-inflammatory Th1 cytokines, Interleukin $1 \beta$ (IL-1ß), interleukin 12 (IL-12), and interferon gamma (IFN- $\gamma$ ) were determined by Rule
Based Medicine multiplex assays. The serum IFN- $\gamma$ levels were in undetectable range in the majority of patient and control samples. Therefore, the comparative analysis focused on IL-1 $\beta$ and IL-12.

Results: Serum IL-6 was higher in SSc patients than controls (fold change $=1.62$, $\mathrm{p}<0.001)$. At the baseline visit, IL-6 positively correlated with hsCRP ( $\mathrm{r}=0.56$, $\mathrm{p}<0.001)$ and modified Rodnan Skin Score $(\mathrm{rS}=0.26, \mathrm{p}=0.037)$ and showed an inverse relationship with disease duration $(r=-0.26, p=0.037)$, while it did not have a significant correlation with forced vital capacity ( $\mathrm{r} s=-0.19, \mathrm{p}=0.126)$. Moreover, no significant correlations were observed with IL-1 $\beta$ and IL-12.

A comparison of regression lines revealed a significant decrease in serum IL-6 levels in the HSCT arm relative to CYC $(p=0.0004)$. By 26 months, the HSCT arm no longer showed upregulation of serum IL-6 relative to controls while the $\mathrm{CYC}$ arm remained upregulated. In contrast, time trends for IL-1 $\beta$ and IL-12 did not differ significantly between arms ( $p$-values $=0.161$ and 0.456 , respectively). (figure 1).
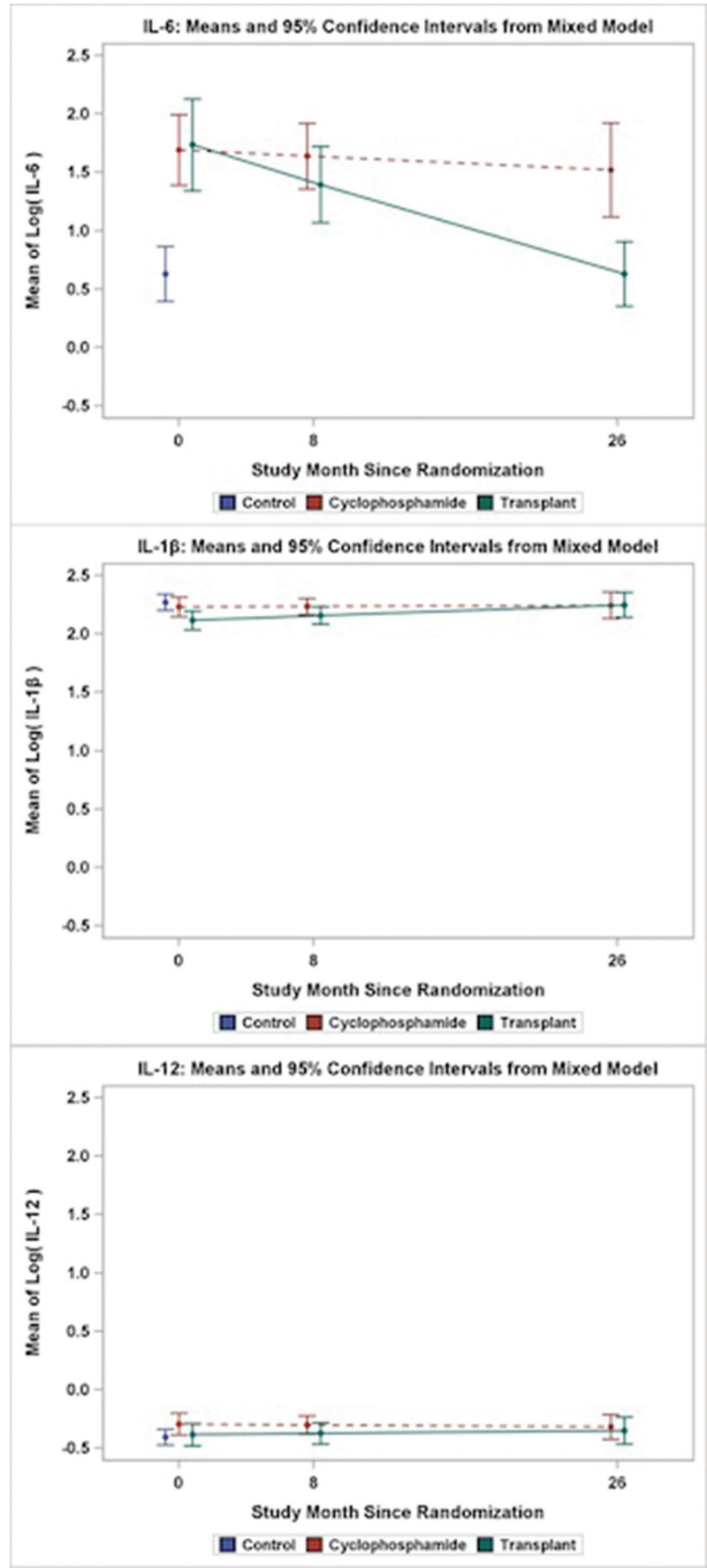

Conclusions: The Serum IL-6 levels decreased significantly 26 months after HSCT, while the two Th1, proinflammatory cytokines did not show simila 